\title{
STRATEGI PENGELOLAAN INFRASTRUKTUR JALAN DI KABUPATEN ACEH UTARA
}

\author{
Herman Fithra ${ }^{1)}$, Tantawi ${ }^{2)}$ \\ Jurusan Teknik Sipil Universitas Malikussaleh \\ email: $\underline{\text { hithra@unimal.ac.id }{ }^{1)} \text {, Awieanggara@gmail.com }}{ }^{21}$
}

\begin{abstract}
Abstrak
Ketersediaan jalan yang baik dan stabil berpengaruh terhadap kelancaran lalulintas. Pengelolaan yang baik serta pemeliharaan jalan yang terus menerus mampu mempertahankan umur rencana jalan. Mengingat dana yang sangat terbatas yang dialokasikan oleh Pemerintah Kabupaten Aceh Utara setiap tahunnya untuk pemeliharaan jalan, maka perlu dilakukan skala prioritas pelaksanaan pemeliharaan jalan yang ada. Penelitian ini dilakukan untuk mengetahui urutan prioritas penanganan pemeliharaan jalan, berdasarkan data survei yang dianalisis dengan skala Likert. Parameter yang diperhitungkan meliputi kondisi permukaan jalan, lalulintas harian rata-rata, kapasitas jalan dan tingkat pelayanan jalan, dilakukan dengan metode survei dan pengumpulan data di lapangan. Analisa data untuk dapat mengetahui nilai urutan prioritas berdasarkan parameter yang telah ditentukan. Skala prioritas pemeliharaan jalan dilakukan berdasarkan kondisi permukaan jalan dan lalulintas harian rata-rata. Urutan dari skala prioritas pemeliharaan jalan adalah ruas jalan Krueng ManeSawang 14 poin (1), ruas jalan Sawang-Riseh Tunong 11 poin (2), ruas jalan Mane Tunong-Pinto Makmur 10 poin (3), ruast jalan Kuta Meuligo-Blang Reuleung 9 poin (4), ruas jalan Menasah Pulo-Teupin Reuseup 8 poin (5), dan ruas jalan Krueng Mane-Bungkah 7 poin (6). Urutan 1-3 masuk dalam peningkatan jalan dan urutan 4-6 merupakan pemeliharaan berkala.
\end{abstract}

Kata kunci: Pemeliharaan Jalan, Kondisi Permukaan Jalan, dan Lintas Harian Rata-rata

\section{Pendahuluan}

Infrastruktur jalan mempunyai peran yang sangat penting untuk menunjang pertumbuhan ekonomi, berupa pendistribusian barang maupun jasa. Ketersediaan infrastruktur jalan yang baik dan stabil berpengaruh terhadap kelancaran arus lalulintas. Kelancaran lalulintas mendukung stabilnya angkutan barang dan lancarnya distribusi barang sampai ke pelosok desa, sehingga pertumbuhan ekonomi menjadi merata. Oleh karena itu menjadi kewajiban semua pihak untuk menyediakan dan menjaga infrastruktur jalan dalam keadaan baik. Salah satu cara menjaga infrastruktur jalan dalam keadaan baik adalah dengan perawatan. Perawatan infrastruktur jalan seharusnya dilakukan untuk semua ruas jalan, bila terdapat kendala anggaran maka dapat dilakukan skala prioritas. Pengelolaan yang baik serta pemeliharaan jalan yang terus menerus mampu mempertahankan umur rencana jalan sesuai dengan yang direncanakan.

Pemerintah Kabupaten Aceh Utara melalui satuan kerja Dinas Bina Marga Bidang Pemeliharaan Jalan dan Jembatan Kabupaten Aceh Utara, selama ini mempunyai kendala yang sangat dilematis, yaitu ketidakseimbangnya dana yang tersedia dengan tingkat kerusakan jalan yang terjadi. Selain itu dalam usulan kegiatan pemeliharaan jalan hanya diwujudkan dalam bentuk usulan pengajuan program penanganan jalan pada Musyawarah Perencanaan Pembangunan Daerah (Musrenbang) dan Anggaran Biaya Tambahan (ABT) dalam menentukan prioritas 
usulan kegiatan pemeliharaan jalan. Hal tersebut semakin menambah panjang daftar urutan pemeliharaan jalan. Agar alokasi dana yang terbatas memberikan manfaat yang sebesar-besarnya untuk tujuan penyelenggaraan penanganan jalan, maka perlu dipertimbangkan prioritas pelaksanaan program penanganan jalan pada ruas-ruas jalan yang ada, paling tidak dapat digunakan untuk pemeliharaan jalan yang sifatnya mempertahankan kinerja ruas jalan sehingga memberikan rasa aman dan kenyamanan bagi pengguna jalan.

Berdasarkan kondisi tersebut, maka penelitian ini bertujuan menentukan skala prioritas pemeliharaan jalan dari beberapa parameter yang ditinjau. Hasil dari penelitian diharapkan dapat memberikan jawaban tentang skala prioritas pemeliharaan jalan.

\section{Tinjauan Kepustakaan}

\subsection{Parameter Mencari Prioritas Pemeliharaan Jalan}

\subsubsection{Permukaan Kondisi Jalan}

Kondisi jalan merupakan keadaan jalan pada suatu ruas jalan. Untuk menentukan penilai kondisi jalan dapat dilakukan dengan menggunakan persamaan density. Density adalah presentase luas atau panjang total dari suatu jenis kerusakan terhadap luas atau panjang total bagian jalan yang di ukur dalam meter persegi atau meter luas (Shahin,1994). Persamaan menhitung nilai density sebagai berikut:

dimana:

$$
\text { Density }=\frac{A d}{A s} \times 100 \%
$$

$$
\begin{aligned}
& A d=\text { Luas total jenis kerusakan untuk tiap tingkat kerusakan }\left(\mathrm{m}^{2}\right) \\
& A s=\text { Luas total segmen }\left(\mathrm{m}^{2}\right)
\end{aligned}
$$

\subsubsection{Lalu Lintas Harian Rata-rata}

Manual Kapasitas Jalan Indonesia(1997) Lalulintas harian rata-rata adalah volume lalulintas rata-rata dalam satu hari. Volume lalulintas didefinisikan sebagai jumlah kendaraan yang melewati satu titik pengamatan selama satu satuan waktu (hari, jam, atau menit). Volume lalulintas yang diperoleh dari hasil penelitian kemudian dikonversikan kedalam Satuan Mobil Penumpang (SMP), untuk kendaraan berat dikalikan dengan 1,3, kendaraan ringan dikalikan dengan 1,0 , sedangkan sepeda motor dan becak motor dikalikan dengan 0,2. Nilai LHR dapat dihitung dengan menggunakan persamaan 2 .

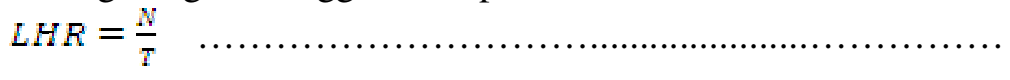

dimana:

LHR = Lalulintas harian rata-rata (smp/jam)

$N \quad=$ Volume lalulintas selama pengamatan (smp)

$T \quad=$ Lamanya pengamatan (jam)

\subsubsection{Kapasitas}

Kapasitas jalan sangat erat kaitannya dalam menampung arus lalulintas dan juga dipengaruhi oleh faktornya. Persamaan untuk penentuan kapasitas jalan:

$$
\mathrm{C}=\operatorname{cox} \mathrm{FCw} x \operatorname{FCsp} x \mathrm{FCsf}
$$


dimana:

$C \quad=$ Kapasitas (smp/jam)

Co $=$ Kapasitas dasar (smp/jam)

$F C w=$ Faktor penyesuaian kapasitas akibat lebar jalur lalulintas

$F C s p=$ Faktor penyesuaian kapasitas akibat pemisah arah

$F C s f=$ Faktor penyesuaian kapasitas akibat hambatan samping

\subsubsection{Tingkat Pelayanan}

Tingkat pelayanan menyatakan tingkat kualitas arus lalulintas yang sesungguhnya terjadi. Tingkat ini dinilai oleh pengemudi atau penumpang berdasarkan tingkat kemudahan dan kenyamanan pengemudi. Tingkat pelayanan suatu jalan menunjukkan kualitas jalan di ukur dari faktor volume lalulintas dan derajat kejenuhan. Manual Kapasitas Jalan Raya (1997), derajat kejenuhan adalah rasio volume lalulintas terhadap kapasitasnya. Gambaran ini menunjukkan suatu ruas jalan mempunyai masalah atau tidak. Persamaan mencari derajat kejenuhan adalah.

$$
\begin{array}{cl}
D_{s}=\frac{v}{c} & \ldots \ldots \ldots \ldots \ldots \ldots \ldots \ldots \\
\text { dimana: } & \\
\text { DS } & =\text { Derajat kejenuhan } \\
\text { V } & =\text { Volume lalulintas } \\
\text { C } & =\text { Kapasitas }
\end{array}
$$

\subsection{Skala Likert}

Skala Likert adalah skala psikometrik yang merupakan salah satu teknik yang dapat digunakan dalam evaluasi suatu program atau kebijakan perencanaan. Rensis Likert telah mengembangkan sebuah skala untuk mengukur sikap masyarakat di tahun 1932 yang sekarang terkenal dengan skala Likert. Pada evaluasi, skala Likert digunakan untuk menilai keberhasilan suatu kebijakan atau program, menilai manfaat pelaksanaan suatu kebijakan atau program, mengetahui kepuasan stakeholder terhadap pelaksanaan suatu kebijakan atau program.

Adapun skor yang digunakan pada skala Likert adalah sebagai berikut:

1. Sangat tidak perlu untuk ditangani (skor 1)

2. Tidak perlu untuk ditangani (skor 2)

3. Netral (skor 3)

4. Setuju untuk ditangani (skor 4)

5. Sangat perlu untuk ditangani (skor 5)

Skor skala Likert tersebut, dijadikan acuan dalam pemberian nilai atau skor pada setiap paramater untuk mendapatkan nilai penanganan pemeliharaan jalan.

\section{Metode Penelitian}

\subsection{Metode Pengumpulan Data}

Penelitian ini mengumpulkan data primer berdasarkan survei lapangan yang dilakukan terhadap enam ruas jalan yang ada di kabupaten Aceh Utara. Data primer yang diperoleh dalam penelitian ini meliputi kondisi permukaan jalan, arus lalulintas dan geometrik enam rusa jalan tersebut. 
Data sekunder diperoleh dari Dinas Bina Marga Bidang Pemeliharaan Jalan dan Jembatan Kabupaten Aceh Utara, berupa peta jaringan jalan kabupaten Aceh utara, daftar ruas-ruas jalan dalam usulan pemeliharaan kabupaten Aceh Utara dan anggaran pemeliharaan jalan tahun 2015 kabupaten Aceh Utara.

\subsection{Analisa dan Pengolahan Data}

\subsubsection{Kondisi Permukaan Jalan}

Analisa dan pengolahan data terhadap kondisi permukaan jalan pada ruasruas jalan yang diteliti dilakukan dengan menghitung tingkat kerusakan jalan menggunakan persamaan density. Density merupakan presentasi luasan dari kerusakan terhadap luasan suatu segmen jalan yang diukur dalam meter persegi.

Berdasarkan dari data tersebut dapat diketahui kondisi permukaan jalan berdasarkan tingkat kerusakan jalan yang menjadi ukuran untuk menentukan nilai penanganan jalan (pemeliharaan). Nilai penanganan jalan berdasarkan skala Likert disusun sebagai berikut.

Tabel 1 Nilai Penanganan Berdasarkan Kondisi Permukaan Jalan

\begin{tabular}{|c|c|}
\hline $\begin{array}{c}\text { Kondisi Permukaan Jalan } \\
(\%)\end{array}$ & $\begin{array}{c}\text { Nilai Penanganan Kondisi } \\
\text { Permukaan Jalan }\end{array}$ \\
\hline$>30 \%$ & 5 \\
\hline $20-30 \%$ & 4 \\
\hline $15-20 \%$ & 3 \\
\hline $10-15 \%$ & 2 \\
\hline$<10 \%$ & 1 \\
\hline
\end{tabular}

\subsubsection{Lintas Harian Rata-rata (LHR)}

Pengolahan data terhadap LHR pada enam ruas jalan yang diteliti dilakukan dengan melakukan survei volume lalulintas harian yang melintas titik pengamatan. Pengelompokkan waktu survei dilakukan dalam jam-jaman (per 1 jam). Besar atau kecilnya jumlah pengguna jalan yang dihitung per 1 jam kemudian dijumlahkan sehingga diperoleh rekapitulasi jumlah pengguna jalan selama 3 hari, dimana pada tiap hari pengamatan selama 6 jam. Waktu pengamatan mulai jam 08.00 wib sampai dengan 18.00 wib, dari waktu survei tersebut diperoleh lintas harian rata-rata untuk enam ruas jalan yang di survei di kabupaten Aceh Utara.

Berdasarkan dari data tersebut diketahui nilai LHR dan urutan penilaian berdasarkan skala Likert disusun sebagai berikut.

Tabel 2 Nilai Penanganan Jalan Berdasarkan LHR

\begin{tabular}{|c|c|}
\hline LHR (smp/jam) & Nilai Penanganan LHR \\
\hline $0-50$ & 1 \\
\hline $50-100$ & 2 \\
\hline $100-200$ & 3 \\
\hline $200-500$ & 4 \\
\hline$\geq 500$ & 5 \\
\hline
\end{tabular}




\subsubsection{Kapasitas Jalan}

Analisis data terhadap kapasitas jalan yaitu mengetahui jumlah maksimum arus lalulintas yang dapat melewati suatu penampang jalan pada jalur jalan selama 1 jam. Beragamnya kondisi geometrik jalan, kendaraan, pengendara dan kondisi lingkungan maka kondisi tersebut perlu disesuaikan kembali dengan beberapa faktor yang direkomendasikan MKJI, 1997. Setelah nilai kapasitas dasar dan faktor penyesuaian lainnya didapat, maka kapasitas jalan dapat dihitung. Kapasitas jalan sangat menentukan nilai pelayanan jalan terhadap lalulintas.

Nilai kapasitas jalan sangat menentukan skala prioritas penanganan jalan. Semakin besar nilai kapasitas jalan maka semakin besar nilai penanganan jalan dan semakin kecil nilai kapasitas jalan maka semakin kecil nilai penanganan jalan. Nilai penanganan jalan dapat diurutkan berdasarkan skala Likert disusun sebagai berikut.

Tabel 3 Nilai Penanganan Jalan Berdasarkan Kapasitas Jalan

\begin{tabular}{|c|c|}
\hline Kapasitas Jalan (smp/jam) & $\begin{array}{c}\text { Nilai Penanganan } \\
\text { Kapasitas Jalan }\end{array}$ \\
\hline $0-500$ & 1 \\
\hline $500-1.000$ & 2 \\
\hline $1.000-2.000$ & 3 \\
\hline $2.000-3.000$ & 4 \\
\hline$\geq 3.000$ & 5 \\
\hline
\end{tabular}

\subsubsection{Pelayanan Jalan}

Analisis dan pengolahan data terhadap tingkat pelayanan yaitu mengetahui tingkat kenyamanan pengguna jalan. Tingkat pengguna jalan dapat diketahui berdasarkan dari nilai derajat kejenuhan. Nilai derajat kejenuhan diperoleh dari volume lalulintas dibagi dengan kapasitas jalan. Berdasarkan derajat kejenuhan dapat ditentukan nilai penanganan jalan pada setiap ruas jalan yang diteliti.

Nilai penanganan jalan dari pelayanan jalan dengan urutan skala Linkert disusun sebagai berikut.

Tabel 4 Nilai Penanganan Jalan Berdasarkan Derajat Kejenuhan

\begin{tabular}{|c|c|}
\hline Derajat Kejenuhan (DS) & $\begin{array}{c}\text { Nilai Penanganan Derajat } \\
\text { Kejenuhan }\end{array}$ \\
\hline $0-0,2$ & 1 \\
\hline $0,2-0,4$ & 2 \\
\hline $0,4-0,6$ & 3 \\
\hline $0,6-0,8$ & 4 \\
\hline$\geq 0,8$ & 5 \\
\hline
\end{tabular}

Setelah semua ruas jalan mendapatkan hasil berdasarkan parameter kondisi permukaan jalan, LHR, kapasitas jalan dan pelayanan jalan, selanjutnya dilakukan pengolahan data untuk menentukan urutan prioritas pemeliharaan jalan. Untuk menentukan pemilihan urutan prioritas pemeliharaan jalan dilakukan dengan menjumlahkan setiap parameter dari setiapa ruas-ruas jalan yang diteliti, sampai didapat nilai totalnya. 
Berdasarkan pengolahan data tersebut dihasilkan urutan prioritas penanganan pemeliharaan jalan. Ruas jalan yang mendapatkan poin dengan nilai tertinggi adalah menjadi prioritas pertama dan akhirnya tersusun suatu daftar prioritas ruas-ruas jalan yang mendapatkan penanganan dan jenis penanganannya. Pada prioritas 1 sampai dengan 3 dimasukkan kedalam program peningkatan, berupa rekonstruksi pembangunan jalan sedangkan pada prioritas 4 sampai dengan 6 dimasukkan kedalam program pemeliharaan berkala, berupa perbaikan pada beberapa segmen jalan yang rusak.

\section{Hasil dan Pembahasan}

\subsection{Kondisi Permukaan Jalan}

Kondisi permukaan jalan pada setiap ruas jalan. Ruas jalan Mane TunongPinto Makmur tingkat kerusakan jalan adalah 20,27\%, mendapat nilai penanganan jalan 4, ruas jalan Kuta Meuligo-Blang Reuleung tingkat kerusakan jalan 17,42\% mendapat nilai penanganan jalan 3. Tingkat kerusakan jalan terbesar pada ruas jalan Sawang-Riseh Tunong sebesar 64,19\% mendapat nilai terbesar dalam nilai penanganan pemeliharaan jalan 5, sedangkan nilai tingkat kerusakan jalan terkecil pada ruas jalan Krueng Mane-Bungkah sebesar 7,03\% dan mendapat nilai penanganan jalan 1. Adapun nilai kondisi permukaan jalan pada setiap ruas jalan lebih lengkap diperlihatkan pada tabel berikut:

Tabel 5 Rekapitulasi Nilai Kondisi Permukaan Jalan

\begin{tabular}{|c|l|c|c|}
\hline No & \multicolumn{1}{|c|}{ Nama Jalan } & $\begin{array}{c}\text { Tingkat } \\
\text { Kerusakan Jalan } \\
(\%)\end{array}$ & $\begin{array}{c}\text { Nilai } \\
\text { Penanganan } \\
\text { Jalan }\end{array}$ \\
\hline 1. & Jalan Krueng Mane - Bungkah & $7,03 \%$ & 1 \\
\hline 2. & Jalan Menasah Pulo - Teupin Reuseup & $10,24 \%$ & 2 \\
\hline 3. & Jalan Kuta Meuligo - Blang Reuleung & $17,42 \%$ & 3 \\
\hline 4. & Jalan Mane Tunoeng - Pinto Makmur & $20,27 \%$ & 4 \\
\hline 5. & Jalan Krueng Mane - Sawang & $38,92 \%$ & 5 \\
\hline 6. & Jalan Sawang - Riseh Tunong & $64,19 \%$ & 5 \\
\hline
\end{tabular}

\subsection{Lalulintas Harian Rata-rata (LHR)}

Berdasarkan hasil pengamatan di lapangan diperoleh nilai LHR pada setiap ruas jalan dengan nilai yang variatif. Ruas jalan Mane Tunoeng-Pinto Makmur LHR sebesar 95,78 smp/jam, ruas jalan Kuta Meuligo-Blang Reuleung nilai LHR sebesar 63,93 smp/jam. Adapun nilai LHR pada setiap ruas jalan diperlihatkan pada tabel sebagai berikut.

Tabel 6 Rekapitulasi Nilai LHR

\begin{tabular}{|c|l|c|c|}
\hline No & \multicolumn{1}{|c|}{ Nama Jalan } & $\begin{array}{c}\text { LHR } \\
(\text { smp/jam })\end{array}$ & $\begin{array}{c}\text { Nilai } \\
\text { Penanganan } \\
\text { Jalan }\end{array}$ \\
\hline 1. & Jalan Mane Tunoeng - Pinto Makmur & 95,78 & 2 \\
\hline 2. & Jalan Kuta Meuligo - Blang Reuleung & 63,93 & 2 \\
\hline 3. & Jalan Krueng Mane - Bungkah & 81,56 & 2 \\
\hline 4. & Jalan Menasah Pulo - Teupin Reuseup & 51,08 & 2 \\
\hline 5. & Jalan Sawang - Riseh Tunong & 76,90 & 2 \\
\hline 6. & Jalan Krueng Mane - Sawang & 207,36 & 4 \\
\hline
\end{tabular}

Strategi Pengelolaan Infrastruktur Jalan di Kabupaten Aceh Utara - Herman Fithra, 
Nilai LHR tertinggi diperoleh pada ruas jalan Krueng Mane - Sawang dengan nilai penanganan jalan 4, ruas jalan Mane Tunoeng-Pinto Makmur, ruas jalan Kuta Meuligo-Blang Reuleung, ruas jalan Krueng Mane-Bungkah, ruas jalan Menasah Pulo-Teupin Reuseup dan ruas jalan Sawang-Riseh Tunong masingmasing mendapat nilai penanganan jalan 2 .

\subsection{Kapasitas Jalan}

Hasil analisis kapasitas jalan sebesar $1.882 \mathrm{smp} / \mathrm{jam}$ untuk empat ruas jalan, $1.822 \mathrm{smp} / \mathrm{jam}$ untuk satu ruas jalan dan tertinggi $2.370 \mathrm{smp} / \mathrm{jam}$ untuk satu ruas jalan. Kapasitas jalan sebesar $1882.3 \mathrm{smp} / \mathrm{jam}$, masing-masing mendapat nilai penanganan jalan 3 dan kapasitas jalan 2369.6 smp/jam mendapat nilai penanganan jalan 4. Adapun nilai kapasitas jalan pada setiap ruas jalan diperlihatkan pada tabel berikut.

Tabel 7 Rekapitulasi Nilai Kapasitas Jalan

\begin{tabular}{|l|l|c|c|}
\hline No & \multicolumn{1}{|c|}{ Nama Jalan } & $\begin{array}{c}\text { Kapasitas } \\
(\text { smp/jam })\end{array}$ & $\begin{array}{c}\text { Nilai Penanganan } \\
\text { Jalan }\end{array}$ \\
\hline 1. & Jalan Mane Tunong - Pinto Makmur & 1.882 & 3 \\
\hline 2. & Jalan Kuta Meuligo - Blang Reuleung & 1.882 & 3 \\
\hline 3. & Jalan Krueng Mane - Bungkah & 1.882 & 3 \\
\hline 4. & Jalan Menasah Pulo - Teupin Reuseup & 1.882 & 3 \\
\hline 5. & Jalan Sawang - Riseh Tunong & 1.822 & 3 \\
\hline 6. & Jalan Krueng Mane - Sawang & 2.370 & 4 \\
\hline
\end{tabular}

Berdasarkan hasil tersebut nilai tertinggi penanganan jalan berada pada ruas jalan Krueng Mane-Sawang dengan nilai 4, sedangkan pada ruas jalan Mane Tunong-Pinto Makmur, ruas jalan Kuta Meuligo-Blang Reuleung, ruas jalan Krueng Mane-Bungkah, ruas jalan Menasah Pulo-Teupin Reuseup dan ruas jalan Sawang-Riseh Tunong mendapat nilai penanganan jalan 3. Ruas jalan Krueng Mane-Sawang adalah jalan yang menghubungkan antar kecamatan ke jalan nasional.

\subsection{Tingkat Pelayanan}

Berdasarkan hasil perhitungan diperoleh nilai derajat kejenuhan pada setiap ruas jalan. Untuk ruas jalan Mane Tunoeng-Pinto Makmur diperoleh nilai derajat kejenuhan sebesar 0,05 ruas jalan Kuta Meuligo-Blang Reuleung diperoleh nilai derajat kejenuhan sebesar 0,03 . Adapun nilai derajat kejenuhan pada setiap ruas jalan diperlihatkan pada tabel sebagai berikut:

Tabel 8 Rekapitulasi Nilai Derajat Kejenuhan

\begin{tabular}{|c|l|c|c|}
\hline No & \multicolumn{1}{|c|}{ Nama Jalan } & $\begin{array}{c}\text { Derajat Kejenuhan } \\
\text { (DS) }\end{array}$ & $\begin{array}{c}\text { Nilai } \\
\text { Penanganan } \\
\text { Jalan }\end{array}$ \\
\hline 1. & Jalan Mane Tunoeng - Pinto Makmur & 0.05 & 1 \\
\hline 2. & Jalan Kuta Meuligo - Blang Reuleung & 0,03 & 1 \\
\hline 3. & Jalan Krueng Mane - Bungkah & 0,04 & 1 \\
\hline 4. & Jalan Menasah Pulo - Teupin Reuseup & 0,03 & 1 \\
\hline 5. & Jalan Sawang - Riseh Tunong & 0,04 & 1 \\
\hline 6. & Jalan Krueng Mane - Sawang & 0,09 & 1 \\
\hline
\end{tabular}

Strategi Pengelolaan Infrastruktur Jalan di Kabupaten Aceh Utara - Herman Fithra, Tantawi 
Berdasarkan hasil tersebut nilai derajat kejenuhan tertinggi diperoleh pada ruas jalan Krueng Mane-Sawang sebesar 0,09 sedangkan nilai derajat kejenuhan terkecil diperoleh pada ruas jalan Kuta Meuligo-Blang Reuleung dan jalan Menasah Pulo-Teupin Reuseup sebesar 0,03 dan semua ruas jalan mendapat nilai penanganan pemeliharaan jalan 1.

\subsection{Urutan Skala Prioritas}

Setelah kesemua parameter penentuan skala prioritas dihitung, maka nilai dari setiap parameter tersebut dijumlahkan. Jumlah dari keseluruhan parameter dengan nilai tertinggi menjadi skala prioritas pertama dari pemeliharaan jalan, begitu pula sebaliknya nilai yang terendah menjadi prioritas terakhir pemeliharaan jalan. Adapun hasil yang didapat dari penelitian ini dapat dilihat pada tabel berikut ini.

Tabel 9 Rekapitulasi Hasil Analisis

\begin{tabular}{|c|c|c|c|c|c|c|c|c|c|}
\hline & \multicolumn{2}{|c|}{$\begin{array}{c}\text { Kondisi } \\
\text { Permukaan Jalan }\end{array}$} & \multicolumn{2}{|c|}{ LHR } & \multicolumn{2}{c|}{ Kapasitas Jalan } & \multicolumn{2}{c|}{$\begin{array}{c}\text { Tingkat } \\
\text { Pelayanan }\end{array}$} & $\begin{array}{c}\text { Total } \\
\text { Nilai dan } \\
\text { Urutan } \\
\text { Nama Ruas Jalan }\end{array}$ \\
$\begin{array}{c}\text { Tingkat } \\
\text { Kerusakan } \\
(\%)\end{array}$ & Nilai & $\begin{array}{c}\text { LHR } \\
(\text { smp/jam) }\end{array}$ & Nilai & $\begin{array}{c}\text { Kapasitas } \\
(\text { smp/jam) }\end{array}$ & Nilai & $\begin{array}{c}\text { Derajat } \\
\text { Kejenuhan }\end{array}$ & Nilai & $\begin{array}{c}\text { Skala } \\
\text { Prioritas }\end{array}$ \\
\hline $\begin{array}{c}\text { Krueng Mane - } \\
\text { Sawang }\end{array}$ & 38,92 & 5 & 203,36 & 4 & 2370 & 4 & 0,08 & 1 & $14 / 1$ \\
\hline $\begin{array}{c}\text { Sawang - Riseh } \\
\text { Tunong }\end{array}$ & 64,19 & 5 & 76,90 & 2 & 1.822 & 3 & 0,04 & 1 & $11 / 2$ \\
\hline $\begin{array}{c}\text { Mane Tunoeng - } \\
\text { Pinto Makmur }\end{array}$ & 20,27 & 4 & 95,78 & 2 & 1.882 & 3 & 0,05 & 1 & $10 / 3$ \\
\hline $\begin{array}{c}\text { Kuta Meuligo - } \\
\text { Blang Reuleung }\end{array}$ & 17,42 & 3 & 63,93 & 2 & 1.882 & 3 & 0,03 & 1 & $9 / 4$ \\
\hline $\begin{array}{c}\text { Menasah Pulo - } \\
\text { Teupin Reuseup }\end{array}$ & 10,24 & 2 & 51,08 & 2 & 1.882 & 3 & 0,03 & 1 & $8 / 5$ \\
\hline $\begin{array}{c}\text { Krueng Mane - } \\
\text { Bungkah }\end{array}$ & 7,03 & 1 & 81,56 & 2 & 1.882 & 3 & 0,04 & 1 & $7 / 6$ \\
\hline
\end{tabular}

Berdasarkan hasil dari analisis tersebut ruas jalan Krueng Mane-Sawang menjadi skala prioritas utama dalam penanganan pemeliharaan jalan. Hal ini disebabkan jalan tersebut mendapat nilai tertinggi sebesar 14 poin, sedangkan skala prioritas terakhir pada ruas jalan Krueng Mane-Bungkah dikarenakan jalan tersebut mendapat nilai terendah 7 poin.

Urutan skala prioritas dari keseluruhan ruas jalan yang diteliti di kabupaten Aceh Utara adalah ruas jalan Krueng Mane-Sawang (1), ruas Jalan Sawang-Riseh Tunong (2), ruas Jalan Mane Tunong-Pinto Makmur (3), ruas Jalan Kuta Meuligo-Blang Reuleung (4), ruas Jalan Menasah Pulo-Teupin Reuseup (5), dan ruas Jalan Krueng Mane-Bungkah (6).

Parameter yang sangat menentukan skala prioritas pemeliharaan jalan berdasarkan data survei dan analisis data di jalan-jalan kabupaten Aceh Utara adalah nilai LHR. Nilai LHR sangat skala prioritas pemeliharaan jalan disebabkan kebutuhan masyarakat akan keberadaan insfrastruktur jalan adalah faktor penting penggerak roda ekonomi, jasa, distribusi logistik dan hubungan sosial. 
Dari Tabel 9 diatas terlihat bahwa ruas jalan Krueng Mane - Sawang mempunyai LHR yang sangat tinggi dibandingkan lima ruas jalan lainnya. Sehingga mempunyai nilai total dalam urutan skala prioritas jauh dari ruas jalan lainnya. Faktor selanjutnya yang mempengaruhi urutan skala prioritas pemeliharaan jalan adalah kondisi permukaan jalan. Ruas jalan Krueng ManeSawang dan ruas jalan Sawang-Riseh Tunong yang kondisi permukaan jalannya sudah rusak > dari 30\% memberikan nilai yang besar untuk skala prioritas pemeliharaan jalan. Selanjutnya kapasitas jalan yang mencapai $>2.300 \mathrm{smp} / \mathrm{jam}$ memberikan pengaruh penilaian skala prioritas pemeliharaan jalan. Sementara pengaruh derajak kejenuhan pada ruas jalan-jalan di kabupaten Aceh Utara tidak memberikan pengaruh yang berarti dalam penentuan skala prioritas pemeliharaan jalan.

\section{Kesimpulan dan Saran}

\subsection{Kesimpulan}

Berdasarkan dari hasil penelitian dan pembahasan yang telah dilakukan maka dapat diambil beberapa kesimpulan sebagai berikut :

1. Strategi penentuan penanganan pemeliharaan infrastruktur jalan selayaknya menggunakan urutan skala prioritas, disebabkan keterbatasan dana yang tersedia;

2. Dalam strategi penentuan skala prioritas pemeliharaan infrastruktur jalan faktor yang paling bepengaruh adalah besarnya LHR;

3. Karena keterbatasan dana strategi penentuan penanganan pemeliharaan infrastruktur jalan, dapat berupa peningkatan dan pemeliharaan berkala saja;

4. Ruas jalan Krueng Mane - Sawang, ruas jalan Sawang - Riseh Tunong dan ruas jalan Mane Tunoeng - Pinto Makmur pemeliharaan infrastruktur jalan berupa peningkatan;

5. Ruas jalan Kuta Meuligo - Blang Reuleng, ruas jalan Menasah Pulo - Teupin Reuseup dan ruas keenam jalan Krueng Mane - Bungkah pemeliharaan infrastruktur jalan berupa pemeliharaan berkala.

\subsection{Saran}

Berdasarkan hasil penelitian dapat diberikan saran-saran sebagai rekomendasi berupa :

1. Diperlukan pemantauan dan pengamatan kerusakan secara rutin, untuk segera dilakukan perbaikan agar kerusakan tidak terus melebar;

2. Supaya penelitian ini menjadi lebih lengkap, sebaiknya perlu dilakukan penambahan parameter-parameter lainnya untuk penentuan skala prioritas pemeliharaan jalan;

3. Untuk memperoleh hasil yang lebih akurat pada pengambilan data LHR perlu dilakukan pengamatan dengan waktu yang lebih lama dengan pos pengamatan yang lebih banyak.

4. Perlu adanya pengolahan data base jalan secara lebih lengkap meliputi kerusakan, geometrik jalan dan lalulintas yang sewaktu-waktu sangat diperlukan sebagai dasar kegiatan rutin tahunan pemeliharaan jalan. 


\section{Daftar Kepustakaan}

Anonim, 1990, Petunjuk Teknis Perencanaan dan Penyusunan Program Jalan Kabupaten. Surat Keputusan No.77/KPTS/Db/1990, Departemen Pekerjaan Umum, Direktorat Jenderal Bina Marga, Jakarta

Anonim, 1990, Tata Cara Penyusunan Program Pemeliharaan Jalan Kota No. 018/T/BNKT/1990, Direktorat Jenderal Bina Marga, Direktorat Pembinaan Jalan Kota, Jakarta

Anonim, 1997, Manual Kapasitas Jalan Indonesia, Direktorat Jenderal Bina Marga, Direktorat Pembinaan Jalan Kota, Jakarta

Anonim, 2004, Undang-undang Republik Indonesia Nomor 38 Tahun 2009 Tentang Jalan, Jakarta.

Anonim, 2009, Undang-undang Republik Indonesia Nomor 22 Tahun 2009 Tentang Lalu Lintas dan Angkutan Jalan, Jakarta.

Anonim, 2011, Peraturan Menteri Pekerjaan Umum Nomor 13/PRT/M/2011 Tentang Tata Cara Pemeliharaan dan Penilikan Jalan, Departemen Pekerjaan Umum, Jakarta.

Anonim, 2015, Program Pemeliharaan Jalan dan Jembatan Kabupaten Aceh Utara, Dinas Bina Marga, Bidang Pemeliharaan Jalan dan Jembatan Kabupaten Aceh Utara, Lhoksukon.

Meidia Refiyanni, dkk, 2014, Evaluasi Penanganan Kerusakan Konstruksi Jalan Berdasarkan Jenis Konstruksi dan Beban Lalu Lintas, Thesis, Magister teknik Sipil, Universitas Syiah Kuala, Banda Aceh

Shahin, M.Y, 1994, Pavement Management for Airports, Roads and Parking Lots, Chapman \& Hall, New York.

Sugiyono, 2013, Statistika untuk Penelitian, Alfabeta, Bandung. 